\title{
Development of satiating and palatable high-protein meat products by using experimental design in food technology
}

\author{
Hanne Kristine Sivertsen', Øydis Ueland ${ }^{2} *$ and Frank Westad ${ }^{3}$ \\ 'Department of Food Science \& Technology, University of California, Davis, CA, USA; ${ }^{2}$ Nofima Mat, ÅS, Norway; \\ ${ }^{3}$ CAMO Software AS, Oslo, Norway
}

\begin{abstract}
Background and objectives: Foods high in protein are known to satiate more fully than foods high in other constituents. One challenge with these types of food is the degree of palatability. This study was aimed at developing the frankfurter style of sausages that would regulate food intake as well as being the preferred food choice of the consumer.

Design and measures: 16 sausage varieties with commercial (PE\% 20) or higher amount of protein (PE\% 40), being modified with vegetable fat (3\% of rapeseed oil), and smoked or not, underwent a sensory descriptive analysis, in which the information was used to choose a subsample of four sausages for a satiety test. Twentyseven subjects were recruited based on liking and frequency of sausage consumption. The participants ranged in age from 20 to 28, and in body mass index (BMI) between 19.6 and 30.9. The students were served a sausage meal for five consecutive days and then filled out a questionnaire to describe their feelings of hunger, satiety, fullness, desire to eat an their prospective consumption on a visual analogue scale (VAS) starting from right before, right after the meal, every half hour for $4 \mathrm{~h}$ until the next meal was served, and right after the second meal.

Results and conclusion: The higher protein sausages were less juicy, oily, fatty, adhesive, but harder and more granular than with lower amount of protein. The high-protein sausages were perceived as more satiating the first $90 \mathrm{~min}$ after the first meal. Some indication of satiety effect of added oil versus meat fat. No significant differences in liking among the four sausage varieties.
\end{abstract}

Keywords: satiety; experimental design; meat products

Received: 12 April 20 I0; Revised: 22 September 20I0; Accepted: 26 October 20 I0; Published: 25 November 2010

$\mathrm{O}$ ne avenue toward controlling weight gain among consumers is developing food products that meet consumers' needs - a goal of creating tasty foods that somehow reduce overeating. This can be made possible when food technology teams up with human response research. A certain amount of trade-offs is usually necessary to produce viable products. Through research on human metabolic responses and nutritional requirements, optimal food composition can be determined. In the real world, however, products containing all these attributes may not be possible to produce or they may not be acceptable to the consumer.

A major obstacle for consumers in complying with diets is lack of diversity. Another is that the diet is composed of foods consumers normally wouldn't eat. One strategy to overcome this is to develop healthier versions of products the consumers would normally desire, such as products adapted from typical comfort foods (1). Examples are processed meat products such as sausages or hamburgers (2). Through food technology these products can be modified to become less energy dense, more satiating, but still be palatable.

Different foods and food constituents are known to especially induce satiation; for instance, high levels of dietary proteins in foods have been shown to increase perceived satiety (3-7). Several studies with meat products confirm this (8-10). Johnson and Vickers (8) and Vanderwater and Vickers (9) found that high-protein foods were less liked than low-protein foods, and that when eaten in equal energy amounts, they produced greater sensoryspecific satiety (decreased ratings of pleasantness) than low-protein foods. Consequently, by increasing the level of proteins in food products, an increase in level of satiety and a reduced food intake might be expected. At the same 
time, the degree of liking may be reduced. For instance, processed meat products are influenced negatively in their textural properties and are perceived as less acceptable on taste than similar products without added protein (11).

Lower palatability of high-protein food products can be overcome in a number of ways. One way to improve the texture is to modify the proteins in the formation of the network structures in the sausage by adding biopolymers (12), or by adding a soy protein/carrageenan mix and varying the fat content (13).

Another way is to introduce taste enhancers such as monosodium glutamate (MSG) in combination with inosine-5-monophosphate (IMP-5) (14, 15). Schiffman et al. (16) found that adding $0.5 \mathrm{mM}$ IMP to the MSG increased the preference scores, but did not significantly affect detection thresholds in foods. Smeets et al. (17) discovered that added MSG/IMP to foods decreased the desire to eat in a high-protein diet without affecting hunger or satiety. Luscombe-Marsh et al. (18) connected the "meatiness" of taste to the taste threshold of MSG/ IMP, and that it seemed to predict the liking for the highprotein foods.

Fat is an important ingredient in making food products more acceptable. Low-fat products are generally less acceptable, since important sensory attributes such as succulence and flavor will be altered, and the products perceived as more rubbery, dry, and chewy $(11,13,19)$. This provides a challenge in the development of highprotein food, which needs the extra smoothening effect of fat. In addition, the nutritional contributions of fats are highly relevant, since the consumption of the amount and type of fat have healthy or unhealthy consequences. A high intake of saturated fats, trans fats, can increase the risk of coronary heart disease, while a low intake of polyunsaturated and monounsaturated fatty acids (MUFAs), may increase the risk of inadequate intake of vitamin $\mathrm{E}$ and essential fatty acids (20)

There is some evidence that certain types of fat can affect satiety differently $(7,21,22)$. Thomas and Chapman (7) described it as the varying effect of individual fatty acids in the efficiency of absorption and rate of oxidation. Prospective consumption ratings have been investigated in studies of MUFAs and polyunsaturated fatty acids (PUFAs). One study (23) looked at the satiating effect of peanut oil and canola oil (MUFAs) versus fat sources high in saturated fatty acids (SFAs). They found that hunger ratings after consumption of fat-free muffins were higher than after eating the muffins with added fat (canola oil, peanut oil, or butter), but no differences were observed among the oils. Replacing animal fat with MUFA has also been studied in sausages $(24,25)$, where Kayaardi (24) found that up to $40 \%$ of the beef fat could be replaced with virgin olive oil without altering the sensory quality of Turkish style soudjouk sausages. Reddy et al. (25) assessed the effects of natural fat substitutes, tapiocaline and
Simplesse, on satiety and subsequent food intake in pork sausages, and found that the high energy full-fat sausages led to delayed satiety compared to the reduced energy sausages on the test day and the following day.

Sausages, or hot dogs, are normally consumed on the go and have fast food connotations. This makes sausages appropriate for modifications in order to make dieting less onerous.

In this study we aimed at developing a frankfurter-type sausage (high-protein meat product) that will regulate food intake as well as being a preferred choice of the consumer. Fat type and MSG were added to the experimental design to study their effect on satiety.

\section{Materials and methods}

The study consisted of two parts, sensory descriptive analysis of sausages, and a consumer satiety study.

\section{Products}

The sausages produced for this study were frankfurterstyle, popular among Norwegian consumers. A number of preliminary tests were run on different productions of sausages, varying in levels of protein and in protein sources. The tests involved sensory descriptive analyses, hedonic ratings, and satiety tests. Based on the results from those tests, the sausages in this study were produced according to a factorial design with four factors in two levels $\left(2^{4}\right)$ :

1. Two levels of protein - protein energy percent $(\mathrm{PE} \%)$ 20 and 40

2. Two sources of fat - pork fat, and pork fat with $3 \%$ replaced with rapeseed oil

3. With and without $0.1 \% \mathrm{MSG}+\mathrm{IMP}$ mixture

4. With and without smoking, in order to make the final products similar to commercial varieties

The low-protein level, $\mathrm{PE} \%$ 20, represented the protein level normally used in commercial frankfurter sausages. The high-protein level, $\mathrm{PE} \%$ 40, was chosen based on a preliminary hedonic test with 80 consumers, indicating that levels above $\mathrm{PE} \%$ 40, were not acceptable. The protein source was a combination of casein and whey (3.5\% Romin 90, Rovita, GmbH, Germany), and gelatin (3.1\% Gelita Sol M, Gelita Sweden AS, Sweden). The sausages were isocaloric $(191 \mathrm{kcal} / 100 \mathrm{~g})$. Based on the design, 16 batches of sausages were produced. No carbohydrates were included. The factorial design is presented in Table 1. Note that $\mathrm{PE} \%$, protein $\%$, and fat $\%$ have correlation 1.0 or -1.0 . The $\mathrm{PE} \%$ was chosen as the variable representing these factors in the design.

All sausages were cooked before the smoking process. The smoking of the sausages was done at $65^{\circ} \mathrm{C}$. The following day the sausages were vacuum packaged and frozen at $-18^{\circ} \mathrm{C}$. The sausages were stored between 1 and 
Table 1. List of sausage recipes used in the test

The 16 batches of sausages were made from a factorial design $\left(2^{4}\right)$ : two levels of protein, PE\% (20) and (40) $)^{\text {a }}$; two sources of fat: pork fat (1) and pork fat with $3 \%$ replaced with rapeseed oil (2), with (1) or without (0) $0.1 \%$ MSG + IMP mixture, and with (1) or without (0) smoking procedure.

\begin{tabular}{|c|c|c|c|c|c|c|c|c|}
\hline Sausage descriptions & Abbreviations & Batch & $\mathrm{PE} \%$ & Protein $\%$ & Fat\% & $\begin{array}{c}\text { MSG/IMP } \\
\text { (I) }\end{array}$ & $\begin{array}{c}\text { Pork } \\
(1) / \\
\text { RSoil(2) }\end{array}$ & $\begin{array}{c}\text { Smoked } \\
\text { (I) }\end{array}$ \\
\hline Low protein, pork fat & LpPork & 1 & 20 & 9 & 17.0 & 0 & I & 0 \\
\hline Low protein, rapeseed oil & LpRSoil & 2 & 20 & 9 & 17.0 & 0 & 2 & 0 \\
\hline Low protein, pork fat, MSG + IMP & LpPorkMSG & 3 & 20 & 9 & 17.0 & I & 1 & 0 \\
\hline Low protein, rapeseed oil, MSG + IMP & LpRSoilMSG & 4 & 20 & 9 & 17.0 & I & 2 & 0 \\
\hline High protein, pork fat & HpPork & 5 & 40 & 19 & 12.0 & 0 & 1 & 0 \\
\hline High protein, rapeseed oil & HpRSoil & 6 & 40 & 19 & 12.0 & 0 & 2 & 0 \\
\hline High protein, pork fat, MSG + IMP & HpPorkMSG & 7 & 40 & 19 & 12.0 & I & I & 0 \\
\hline High protein, rapeseed oil, MSG + IMP & HpRSoilMSG & 8 & 40 & 19 & 12.0 & I & 2 & 0 \\
\hline Low protein, pork, smoked & LpPorkS & 9 & 20 & 9 & 17.0 & 0 & 1 & I \\
\hline Low protein, rapeseed oil, smoked & LpRSoilS & 10 & 20 & 9 & 17.0 & 0 & 2 & 1 \\
\hline Low protein, pork, MSG + IMP, smoked & LpPorkMSGS & II & 20 & 9 & 17.0 & $\mathbf{I}$ & I & I \\
\hline Low protein, rapeseed oil, MSG +IMP, smoked & LpRSoilSMSGS & 12 & 20 & 9 & 17.0 & $\mathbf{I}$ & 2 & $\mathbf{I}$ \\
\hline High protein, pork, smoked & HpPorkS & 13 & 40 & 19 & 12.0 & 0 & I & I \\
\hline High protein, rapeseed oil, smoked & HpRSoilS & 14 & 40 & 19 & 12.0 & 0 & 2 & 1 \\
\hline High protein, pork, MSG +IMP, smoked & HpPorkMSGS & 15 & 40 & 19 & 12.0 & $\mathbf{I}$ & $\mathbf{I}$ & $\mathbf{I}$ \\
\hline High protein, rapeseed oil, MSG + IMP, smoked & HpRSoilMSGS & 16 & 40 & 19 & 12.0 & $\mathbf{I}$ & 2 & I \\
\hline
\end{tabular}

${ }^{a}$ The percentage of protein and fat in each batch are adjustments made according to the differences in the PE\%. Abbreviations are included for the four sausage batches being used in the sensory descriptive analysis and the satiety test.

Note: The marked batches were chosen for the satiety test.

3 weeks, during the time in which they were used in the project. Before being used, they were thawed for $12-24 \mathrm{~h}$.

\section{Sensory descriptive analysis by a trained panel}

The trained panel consisted of 10 sensory assessors employed at Nofima Mat AS, with a minimum of 5years experience as tasters. The assessors were selected and trained according to recommendations in ISO (1993) (26). A modified quantitative sensory descriptive analysis was used for the evaluation. The sensory laboratory was designed according to guidelines in ISO (1988) (27) with separate booths and electronic registration of data (CSA, Compusense Five, Version 4,6, Guelph, Ontario, Canada, 1999).

\section{Procedure}

The sausages were heated in a Combi Damper (Electrolux, Comm. Mod AOS016EANQ) at $80^{\circ} \mathrm{C}$ for $15 \mathrm{~min}$ before serving. One-half of a sausage was served in ceramic beakers, covered with a metal lid, and coded with three digit random numbers. The sausage was cut along the side to measure evenness of the cut. Each sample was evaluated in duplicate. Five samples were tested during each session in a completely randomized order. There were six sessions during two consecutive days.
The samples were rated for appearance (evenness/ uniform interior in the cut), odor (intensity of smell, acidic aroma, spicy aroma), color (whiteness/luminance, color hue, color tone/satiation), taste (intensity of taste, meaty taste, acidic taste, salty taste, sweet taste, bitter taste, metallic taste, spicy taste, umami), and texture (hardness, juiciness, fatness, oiliness, adhesiveness, roughness/granularity, cohesiveness, aftertaste). The attributes were quantified on an unstructured scale $(15 \mathrm{~cm})$, anchored in each end with no intensity and high intensity. Marking the intensity of each attribute directly on the screen by a cursor entered the data, and the marked intensities were converted to numbers, from 1 to 9 (CSA, Compusense Five, 1999, Compusense Inc. Guelph, Ontario Canada)

\section{Consumer satiety test \\ Products}

A subset of four sausages from the factorial design was chosen for the consumer satiety test. The smoked version was chosen for all sausages, because most commercial sausages undergo a smoking procedure in Norway. The two levels of protein (PE\% 20 and 40) and the two fat sources (pork fat and pork fat with 3\% replaced with rapeseed oil) were chosen as the most interesting factors 
for the satiety test (highlighted in Table 1). All sausages had MSG/IMP added.

Subjects

Adverts for participants were posted on information boards at the University of Life Sciences, Ås, Norway. All subjects who signed up received a written information and invitation letter to an open introductory meeting. At the introductory meeting further information about the aim and scope of the experiment was provided both orally and in written form. The subjects were informed that they were free to leave the study at any time. They were recruited based on liking and frequency of consumption of sausages and availability to participate in the satiety test lasting 5 full days. On successful completion of the whole study, a gift card was offered.

A total of 27 subjects, students from the University of Life Sciences, ranging in age from 20 to 28 years, 14 women and 13 men, completed the study. The selfreported body mass index (BMI) for both sexes, ranged from 19.6 to 30.9 , with the mean of 23.5 for women and 24.7 for men. The subjects were randomly divided into four groups - the groups received the preload in different order to control for carryover effects (Table 2). On test days, servings were performed in two rounds. Two groups of subjects, A and B (7+7 subjects), showed up $45 \mathrm{~min}$ earlier than the other two groups, C and D $(6+7$ subjects). The same groups were served at the same time throughout the experiment. Otherwise, all subjects followed the same procedure.

\section{Procedure}

The subjects were asked to eat breakfast every day on the test days, between 0600 and $0900 \mathrm{~h}$, but to refrain from eating after the $0900 \mathrm{~h}$. The type of breakfast was the subject's own choice, but he/she was asked to eat the same breakfast on all test days. They were later asked to describe what they ate for breakfast. After $0900 \mathrm{~h}$, they were allowed to drink coffee, tea, or water, with no addition of milk or sugar. The subjects were free to eat what they wanted after the test was over each day. They were also asked not to perform strenuous exercises before the test in the morning or during the time of testing. On arrival at lunchtime, the subjects were asked to fill in a questionnaire and describe their feelings of satiety, hunger, fullness, desire to eat, prospective food consumption, and what they had eaten for breakfast that day. A $100 \mathrm{~mm}$ visual analogue scale (VAS) anchored by "not at all" and "very" was used for each of the appetite measurements.

Upon arrival of the first day, a short introduction to the procedure was given prior to administering the questionnaire and preload. The subjects were placed in sensory booths and served the meal. On the first day, all subjects were served an ad libitum portion of the same sausage, a low-protein sample most similar to a commercial sausage ( $\mathrm{PE} \% 20$ with pork fat). This was done to get an idea of how much each individual subject would eat in a meal. The results from this session were not included in the study. Eighty percent of the amount of sausage eaten was used as the amount of sausage served each subject in the remaining four meals. This allowed the subjects room to give higher scores when eating the highprotein sausages. In the remaining four sessions the subjects were told to eat the total amount of sausage served.

Salad was served as a separate dish on a paper plate. Each subject received $50 \mathrm{~g}$ of iceberg lettuce, ca. $60 \mathrm{~g}$ (one-half) of a tomato, and ca. $60 \mathrm{~g}$ (three $1 \mathrm{~cm}$ slices) of an English cucumber. The sausages were served in deep paper bowls to facilitate weighing. Water was used for drinking during the meal but was not measured.

Immediately following the meal, the subjects received another questionnaire, featuring the same five questions on satiety as in the first questionnaire and, in addition, how much they liked the sausage. The same appetite measures were then recorded every $30 \mathrm{~min}$ during the following $4 \mathrm{~h}$, in total eight times. After $4 \mathrm{~h}$, the subjects were served a second meal consisting of pasta (Combino, fusilli, Lidl Stiftung \& Co. KG, D-74167 Neckarsulm), pasta sauce (Chef-Koch, Fix spaghetti Napoli, Lidl Stiftung \& Co) with minced meat, the same salad as was served with the sausages, and one dinner roll (Hatting, "Norwegian" whole wheat and rye, Hatting Bageri, DK-8700 Horsens, Denmark). The pasta was weighed before serving. Women received $250 \mathrm{~g}$ of pasta

Table 2. Serving order of sausage samples for each group of subjects (A, B, C, and D) each of the 4 test days

\begin{tabular}{|c|c|c|c|c|}
\hline \multirow[b]{2}{*}{ Group/serving time (hour) } & \multicolumn{4}{|c|}{ Group } \\
\hline & Day I & Day 2 & Day 3 & Day 4 \\
\hline $\mathrm{A} / \mathrm{I} 100$ & LpPorkMSG & LpRSoilMSG & HpPorkMSG & HpRSoilMSG \\
\hline $\mathrm{B} / \mathrm{I} 100$ & LpRSoilMSG & HpPorkMSG & HpSRoilMSG & LpPorkMSG \\
\hline $\mathrm{C} / 1145$ & HpPorkMSG & HpRSoilMSG & LpPorkMSG & LpRSoilMSG \\
\hline $\mathrm{D} / \mathrm{I} / 45$ & HpRSoilMSG & LpPorkMSG & LpRSoilMSG & HpPorkMSG \\
\hline
\end{tabular}


Table 3. Nutrient composition (per $100 \mathrm{~g}$ ) of sausage samples in preload and of the dinner (second meal)

\begin{tabular}{lcccc}
\hline Ingredient & $\mathrm{KJ}(\mathrm{kcal})$ & Protein $(\mathrm{g})$ & $\mathrm{CHO}(\mathrm{g})$ & Fat $(\mathrm{g})$ \\
\hline Preload & & & & \\
$\quad$ Sausage LPPorkMSG & $800(191)$ & $9.5 \%$ & 0 & $17.0 \%$ \\
Sausage LPRSoilMSG & $800(191)$ & $9.5 \%$ & 0 & $17.0 \%$ \\
Sausage HpPorkMSG & $800(191)$ & $19.1 \%$ & 0 & $12.7 \%$ \\
Sausage HpRSoilMSG & $799(191)$ & $19.1 \%$ & 0 & $12.7 \%$ \\
Second meal & & & & \\
Minced meat & $820(196)$ & 17.0 & 0 & 24 \\
Pasta sauce & $180(45)$ & 1.0 & 8.5 & 0.5 \\
Fusilli pasta & $1520(358)$ & 12.0 & 75.0 & 1.1 \\
Roll & $\mathrm{I}, 140(270)$ & 8.0 & 47.0 & 2.0 \\
Salad & $54(13)$ & 0.8 & 1.8 & 0.1 \\
\hline
\end{tabular}

and the men $350 \mathrm{~g}$ of pasta. Nutritional composition of the meals is shown in Table 3. Refills were allowed, weighed, and added to the weight from the first serving. After dinner the subjects received the last questionnaire of the day consisting of the same five questions about appetite.

At the end of the project, the subjects filled out a questionnaire, asking on a scale from 1 (not interested) to 9 (very interested), if they would be interested in buying the sausages with the higher amount of protein, because of its satiating effect. The second question was how interesting it would be, for people with weight problems, to buy such sausage products. The subjects were also asked how often they would be interested in eating sausages with higher amounts of protein.

\section{Statistical analysis}

Analysis of variance (ANOVA) mixed model, GLM, with judges as random effect was used on the sensory descriptive data, as evaluated by 10 sensory judges $\times 2$ replicates (SAS Release 6.12 (Copyright (C) 1989-1996 by SAS Institute Inc., Cary, NC, USA, SAS software, 2004).

ANOVA for orthogonal designs was used on the data from the satiety test. The effect of the design factors and their interactions based on the reduced design in the consumer test was calculated (Table 2). The theory behind a basic ANOVA for orthogonal designs can be found in Montgomery (28).

\section{Results}

\section{Sensory descriptive analysis of the sausages}

The smoking procedure produced the largest differences in taste profiles across the sausage samples. Among the non-smoked samples, the attributes that differed significantly and which were found non-significant among the smoked samples were intensity of smell $(p<0.01)$, acidic aroma $(p<0.001)$, smoke aroma $(p<0.05)$ acidic taste $(p<0.001)$, bitter taste $(p<0.05)$, metallic taste $(p<0.01)$, and after taste $(p<0.01)$. Apart from the differences found based on the two protein levels, none of the other factors, fat source or added MSG, seemed to affect the non-smoked samples in a systematic way. The nonsmoked samples with a higher protein level were rated higher for bitter taste, metallic taste, and lower for acidic taste but the differences were very small. Among the smoked samples, the attributes smoke taste $(p<0.05)$ and meat taste $(p<0.05)$ differed significantly, while they did not among the non-smoked samples.

Fig. 1 illustrates the taste profiles of smoked sausages (since the sausages that were used in the satiety test were smoked only the results from the smoked samples are shown here). Only the attributes that were found to significantly differ across the smoked samples are included in the figure. It can be seen that the low-protein samples scored higher for juiciness, fattiness, oiliness, cohesiveness, and whiteness while they scored lower than

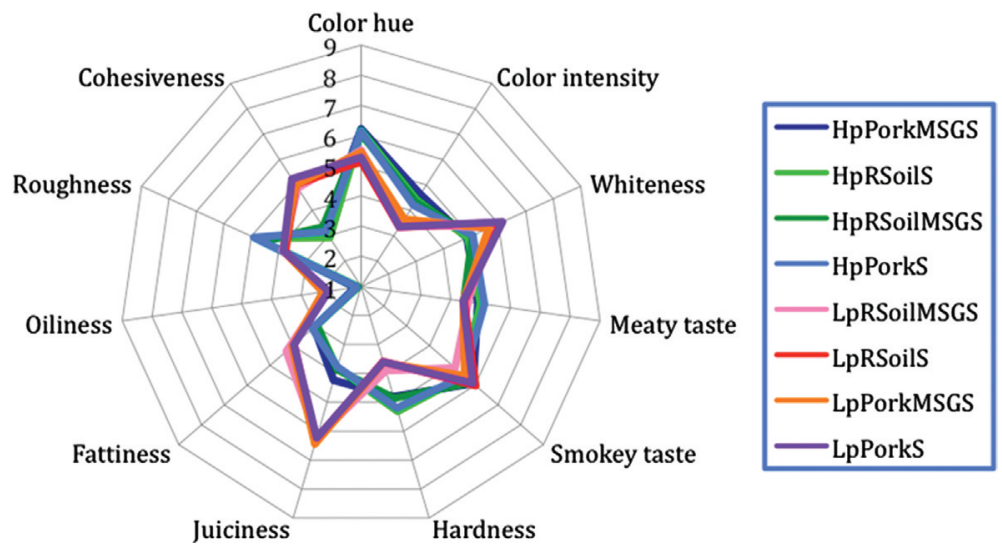

Fig. 1. Cobweb plot - significant $(p<0.05)$ sensory attributes across the smoked sausage samples, $n=33(11$ judges $\times 3$ replicates). 
the high-protein version on hardness, roughness, color intensity, and color hue.

\section{Satiety measures}

Significant differences $(p<0.05)$ were found between sausages with a different amount of protein; for recorded hunger, fullness, satiation, desire to eat, and prospective consumption; just after the sausage meal, after $30 \mathrm{~min}$, and after $1 \mathrm{~h}$ (Fig. 2). For the desire to eat and how much to eat, there were also significant differences, after 2, 2.5, and $3 \mathrm{~h}$. Fig. 2 illustrates changes over time in the degree of hunger, degree of satiety, degree of fullness, degree of desire to eat and the amount to eat.

In general, the largest difference between the sausage varieties can be seen just after the preload and for the next $90 \mathrm{~min}$ for hunger, satiation, and fullness measurements. A higher hunger score, a lower satiety score, a lower fullness score, and a higher desire to eat can be seen for the low-protein sausages. Conversely, the highprotein sausages scored lower on hunger and desire to eat and higher on satiety and fullness. In the remaining time before the second meal, no clear differences in any of the recorded descriptions of satiety can be seen among the different sausages. One exception was for the high-protein sausage with added rapeseed oil after $3 \mathrm{~h}$, which had a lower score of hunger, higher of satiation, and higher score of fullness than the other sausages.

Desire to eat and prospective consumption show a clearer trend across the whole time period. The sausages with a low amount of protein got higher scores throughout the $4 \mathrm{~h}$, meaning that the respondents indicated higher desire to eat and prospective consumption. The high-protein sausage with pork fat got similar but lower scores.

The fat source did not produce any clear significant differences, but a tendency was noted $(p<0.10)$ after 3 , $3.5,4 \mathrm{~h}$; after the second meal for satiation, and after 2.5, 3, and $3.5 \mathrm{~h}$ for desire to eat. Higher satiety scores were given for the sausages with the same amount of protein but with added rapeseed oil compared to only pork fat.

\section{Consumption of the second meal}

Average consumption of pasta at the second meal was $405 \mathrm{~g}$ for women and $420 \mathrm{~g}$ for men. In this study, no effect of protein level or fat source in the preload was seen on subsequent pasta consumption.

\section{Liking and intent to purchase}

No significant difference in liking was noted between the low-protein and high-protein sausage samples. Liking scores were 6.0 for low-protein sausages with pork fat, 6.3 for low-protein sausages with added rapeseed oil, 5.5 for high-protein sausages with pork fat, and 5.6 for highprotein sausages with added rapeseed oil.

The scores of degree of interest for buying sausages with a higher amount of protein were $5.9( \pm 2.7)$ for all students, $6.5( \pm 1.7)$ for women, and $5.2( \pm 2.3)$ for men. When asked how interesting it would be for people with weight problems to buy such sausages, mean scores were $7.7( \pm 1.4)$ for all students, $8.2( \pm 0.8)$ for women, and 7.2 $( \pm 1.8)$ for men. When asked how often they would be interested in eating these sausages, the average answer was once a month. These hedonic results are only based on the replies from 27 students and can only be used as indications.

\section{Discussion}

\section{Sensory descriptors}

This study aimed at investigating the possibility of developing a high-protein sausage that would be satiating, well liked, and acceptable for the consumer as a food product alternative in daily life.

The sensory analysis of the sausages was included to get a clear description of the differences in the sausage varieties due to the four factors in the design: the smoking process, the two protein levels, the fat sources, and the effect of MSG/IMP.

By including the non-smoked samples in the test, we wanted to rule out the possibility of any sensory differences that would otherwise be disguised in the smoking procedure. Although small differences were found among the non-smoked samples, and several attributes among the smoked samples were not found significantly different across the samples, in comparison to the non-smoked samples these differences were not large enough to make an effect on the taste of the smoked samples.

The MSG/IMP effect did not have any impact on the sensory properties alone. The $0.1 \%$ MSG/IMP added to the sausages was low compared to other studies. Most of these studies used consumers as subjects and looked for differences in palatability. Bellisle (14), in her review, found an optimal level between 0.4 and $0.6 \%$ for MSG in unfamiliar foods among Europeans, and a range between 0.1 and $0.75 \%$ MSG for Japanese consumers. Although MSG did not show any effect on the taste attributes, it did not necessarily indicate a no-effect on the palatability level of the sausages in the satiety test as one study on elderly subjects illustrated. The MSG threshold was lower than the detection threshold, but the same concentration affected the preference for the foods with this concentration included than those without (16).

The factor of high- and low-protein levels measured in this study had a pronounced effect on the sensory attributes, specifically the color and the texture attributes. 

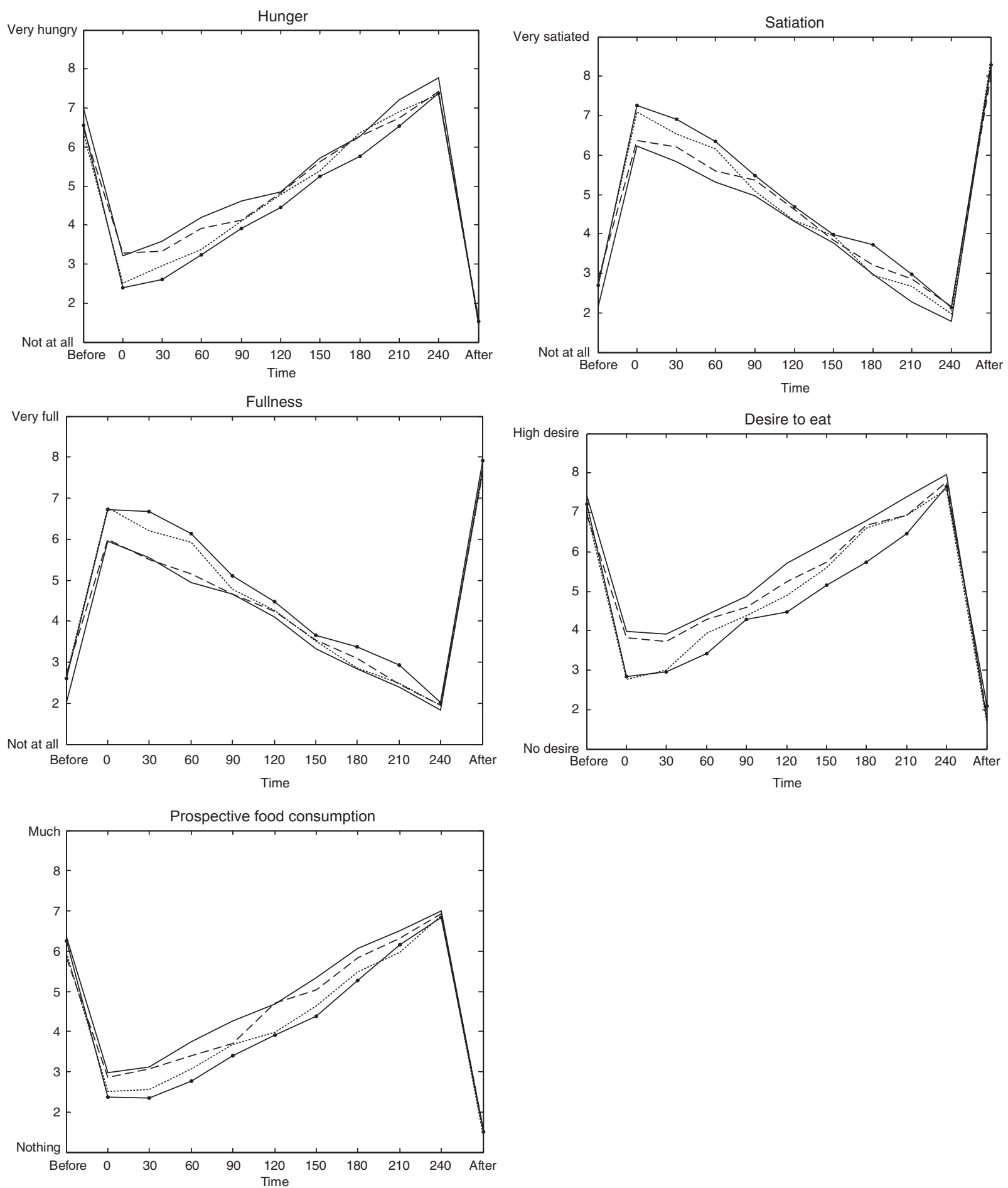

Fig. 2. Average measurements of subjects' $(n=27)$ feelings of hunger, satiation, fullness, desire to eat, and prospective food consumption before and after the pre/load, and for $4 \mathrm{~h}$, until after the second meal (time = minutes). At the first meal one of four varieties of sausage was served: LpPorkMSG (-), low-protein sausage (PE\% 20) with pork fat; LpRSoilMSG (---), low-protein sausage with 3\% substituted rapeseed oil; HpPorkMSG (...), high-protein sausage (PE $\%$ 40) with pork fat; or HpRsoilMSG $(\multimap$, , high-protein sausage with $3 \%$ substituted rapeseed oil.

This can be confirmed in another study (11). In that study, Pietrasik found that the higher the protein content in comminuted scalded sausages, the higher the hardness of the sausage, regardless the fat and starch level.

\section{Satiety measurements}

The main outcome from the satiety test was a higher satiety during the first $90 \mathrm{~min}$ after eating the sausages with high-protein content (PE\% 40), and a tendency that 
the high-protein sausages with rapeseed oil showed a slightly higher satiety level than the sausages made from pork fat only.

In a similar study (17), where the same type sausages were used as the test product, metabolic and hormonal responses to a higher protein intake were measured, and a single high-protein lunch was found not to give any acute effect on satiety through increased concentrations of satiety-related hormones. Still, the satiety VAS scores were significantly higher 30 and $120 \mathrm{~min}$ after the high-protein lunch ( $\mathrm{PE} \%$ 25) compared with the appropriate protein lunch $(\mathrm{PE} \% 10)$.

In our study the reported satiety lasted longer, up to $90 \mathrm{~min}$. This may be more related to satiety (postponing the next meal) than to satiation (terminating the meal) since the sausages were very similar in taste, and according to the liking scores, no large differences in liking occurred between the low-protein and the highprotein sausages. Taste aversion should not be an including factor for differentiating the sausage variables. The sensory specific satiety should also be the same for all sausages because of their similar taste.

The decrease in hunger based on a higher level of protein was also found by Vanderwater and Vickers (9) in yogurt and in a ham sandwich, where the amounts of calories were the same while the level of proteins differed. In these studies the protein source was whey. According to $\mathrm{Hu}(29)$, many short-term studies confirm the evidence that high-protein diets enhance weight loss. Many mechanisms contribute to an increased satiety and a subsequent reduced energy intake. The type of protein will affect them differently.

Red meat and processed meat, like a frankfurter type sausage, are high in SFAs. By replacing some of this fat with an unsaturated fat such as rapeseed oil, these products can improve their nutritional value.

Rapeseed oil is high in MUFAs (61\%) that, like PUFAs, are oxidized in preference to SFAs - this may produce stronger satiety effects. Iyer et al. (30) found no clear indication that this was true since the energy intake after $24 \mathrm{~h}$ was the same after ingesting muffins with peanut oil, canola oil, butter, or fat free. Although they did find a higher rated fullness after canola oil and peanut oil muffins, and lower hunger ratings after butter, canola, and peanut oil muffins in up to $120 \mathrm{~min}$. Other studies confirm the trend that no clear differences in satiety between MUFAs and PUFAs can be found $(21,31)$.

In this study, a difference in satiety between sausages with added rapeseed oil and those with only pork fat lasted up to $90 \mathrm{~min}$. Whether this will have an effect on the energy intake and subsequent weight loss in the longer run will need a longer and more profound research.

Another important factor was the liking of the sausages. As no significant difference in liking occurred for these sausages within this frame of sensory variability, it should be possible to develop sausages that have protein levels of up to $\mathrm{PE} \% 40$ with substitutes of vegetable fat $(3 \%$ in this case), which will give an acceptable taste as compared to similar commercial sausage varieties. Although only a small panel of students was evaluating the liking of these sausages, more research is needed to confirm these findings.

\section{Conclusion}

This study showed that it is possible to produce highprotein comfort food such as frankfurter-type sausages that increase perception of satiety and, thus, has food intake regulatory properties. In order to facilitate weight control, availability of healthier comfort food alternatives will be an asset for subjects' ability to comply with dietary advice.

\section{Acknowledgements}

The authors would like to thank Dr. Janna Bitnes for earlier work in the project, the sensory group at Nofima Mat for performing the analyses, and Tom Chr. Johannessen for producing the sausages.

\section{Conflict of interest and funding}

The authors have not received any funding or benefits from industry or elsewhere to conduct this study.

\section{References}

1. Wansink B, Cheney MM, Chan N. Exploring comfort food preferences across age and gender. Physiol Behav 2003; 79: $739-47$

2. Hagen H. Sausages and beer. In Norwegian [Pølser og øl]. 2007. Tun forlag AS, Oslo.

3. Labayen I, Díez N, Parra D, González A, Martínez JA. Total and endogenous lipid oxidation in obese women during a 10 weeks weight loss program based on a moderately high protein energy-restricted diet. Nutr Res 2004; 24: 7-18.

4. Schoeller DA, Buchholz AC. Energetics of obesity and weight control: does diet composition matter? J Am Diet Assoc 2005; 105: S24-S28.

5. Palou A, Picó C. Overview on functional foods in Europe: strategies, efficacy and safety. Curr Topics Nutra Res 2006; 4: $153-74$

6. Luhovyy BL, Akhavan T, Anderson GH. Whey proteins in the regulation of food intake and satiety. J Am Coll Nutr 2007; 26: $704 \mathrm{~S}-712 \mathrm{~S}$

7. Thomas S, Chapman S. A review of ingredients, physiological mechanisms and measurements involved in the enhancement of satiation. Review No. 60. Chipping Campden, UK: Campden \& Chorleywood Food Research Association Group; 2008.

8. Johnson J, Vickers Z. Factors influencing sensory-specific satiety. Appetite 1992; 19: 15-31.

9. Vanderwater K, Vickers Z. High-protein foods produce greater sensory-specific satiety. Physiol Behav 1994; 59: 579-83.

10. Porrini M, Santangelo A, Crovetti R, Riso P, Testolin G, Blundell JE. Weight, protein, fat, and timing of preloads affect food intake. Physiol Behav 1997; 62: 563-70. 
11. Pietrasik Z. Effect of content of protein, fat and modified starch on binding textural characteristics, and colour of comminuted scalded sausages. Meat Sci 1999; 51: 17-25.

12. Muguruma M, Tsuruoka K, Katayama K, Erwanto Y, Kawahara S, Yamaguchi K, et al. Soybean and milk proteins modified by transglutaminase improves chicken sausage texture even at reduced levels of phosphate. Meat Sci 2003; 63: 191-7.

13. Pietrasik Z, Duda Z. Effect of fat content and soy protein/ carrageenan mix on the quality characteristics of comminuted, scalded sausages. Meat Sci 2000; 56: 181-8.

14. Bellisle F. Glutamate and the UMAMI taste: sensory, metabolic, nutritional and behavioral considerations. A review of the literature published in the last 10 years. Neurosci Biobehav Rev 1999; 23: 423-38.

15. Yamaguchi S, Ninomiya K. Umami and food palatability. Am Soc Nutr Sci 2000: 921S-926S

16. Schiffman SS, Sattely-Miller EA, Zimmerman IA, Graham BG, Erickson RP. Taste perception of monosodium glutamate (MSG) in foods in young and elderly subjects. Physiol Behav 1994; 56: 265-75.

17. Smeets AJ, Soenen S, Luscombe-Marsh ND, Ueland $\varnothing$, Westerterp-Plantenga MS. Energy expenditure, satiety, and plasma ghrelin, glucagon-like, and peptin tyrosine-tyrosine concentrations following a single high-protein lunch. J Nutr 2008; 139: 698-702.

18. Luscombe-Marsh ND, Smeets AJPG, Westerterp-Plantenga MS. Taste sensitivity for monosodium glutamate and an increased liking of dietary protein. Br J Nutr 2008; 99: 904-8.

19. Keeton JT. Low-fat meat products - technological problems with processing. Meat Sci 1994; 36: 261-76.

20. The Report of the Dietary Guidelines Advisory Committee on Dietary Guidelines for Americans, 2005. Available from: http:// www.cnpp.usda.gov/DGAs2005Guidelines.htm [cited 9 November 2010]

21. Kampuis MMJW, Westerterp MS, Saris WHM. Original communication fat-specific satiety in humans for fat high in linoeic acid vs fat high in oleic acid. Eur J Clin Nutr 2001; 55: 499-508.
22. Kamphuis MMJW, Mela DJ, Westerp-Platenga MS. Diacylglycerols affect substrate oxidation and appetite in humans. Am J Clin Nutr 2003; 77: 1133-9.

23. Alfenas RCG, Mattes RO. Effect of fat Sources on satiety. Obes Res 2003; 11: 183-7.

24. Kayaardi S, Gõk V. Effect of replacing beef fat with olive oil on quality characteristics of Turkish soudjouk (sucuk). Meat Sci 2003; 66: 249-57.

25. Reddy S, Kilcast D, Thane C, Church N. Effect of high-energy and reduced energy breakfast comprising fat-substituted foods on appetite, satiety and subsequent nutrient intake. Nutr Food Sci 1996; 5: 30-6.

26. ISO (1993). Sensory analysis: methodology. General guidance for selection, training and monitoring of assessors, Part 1: selected assessors. In ISO-Standard 8586-1. Geneva, Switzerland: The International Organization for Standardization.

27. ISO (1988). Sensory analysis: general guidance for the design of test rooms. In ISO-Standard 3972. Geneva, Switzerland: The International Organization for Standardization.

28. Montgomery DC. Design and Analysis of Experiments, 6th ed. New York: John Wiley \& Sons; 2004.

29. Hu FB. Protein, body weight and cardiovascular health. Am J Clin Nutr 2005; 82: 242S-247S.

30. Iyer SS, Boateng LA, Sales RL, Coelho SB, Lokko P, Monteiro JBR, et al. Effects of peanut oil consumption on appetite and food choice. Int J Obes 2006; 30: 704-10.

31. Flint A, Helt B, Raben A, Toubro S, Astrup A. Effects of different dietary fat types on postprandial appetite and energy expenditure. Obes Res 2003; 11: 1449-55.

* Øydis Ueland

Consumer and Sensory Sciences

Nofima Mat

Osloveien I

No- $1430 \AA$ Å, Norway

Tel: +4799607621

Email: oydis.ueland@nofima.no 